\title{
Punishment following escape and avoidance training '
}

ROBERT S. BEECROFT AND JUDSON S. BROWN

UNIVERSITY OF IOWA

Rats were trained in a runway for five days with a $0,1,2$, or 4-sec delay between grid drop and shock onset followed by four days of extinction with punishment. The 0-sec (escape) Ss showed less resistance to extinction and slower running during extinction.

In the self-punitive paradigm, as studied by Brown, Martin, \& Morrow (1964), Ss are first trained to escape shock that is present in all sections of a runway. Subsequently, when shock is applied to only a portion of the runway grid, the animal is free to remain in the start box or non-electrified parts of the alley and can meet an extinction criterion without being shocked. However, if $\mathrm{S}$ advances through the punishment zone and enters the goal box, he is given another trial. Persistent running in this situation is described as self-punitive behavior.

The introduction of shock in only part of the alley constitutes a change from training trials, all of which involve escape from shock in both the start box and the alley. In an avoidance training paradigm, by contrast, shock is seldom encountered in the start box after the first few trials; if the animal is shocked at all, the shock is experienced somewhere along the alley. The highest degree of similarity between training and punishment testing would obtain for an animal that during training had always run some distance in the alley before receiving shock, but had never completely avoided shock. One method of achieving this condition (cf., Brown \& Van Bruggen, 1967) is to delay onset of shock by an interval long enough to insure the rat is out of the start box and running, although short enough to preclude shock avoidance. In a 6-ft alley (plus start box), a 1-sec delay in shock onset meets this requirement, since Ss trained with this delay seldom run fast enough to avoid shock. With longer avoidance intervals most rats do learn to avoid, although when they do fail shock is received in the last part of the alley. In this study a comparison was made between escape training, where during training shock was present from start to goal box, and avoidance training involving three shock-delay intervals such that running in the absence of shock could occur during training. It was predicted that resistance to extinction with punishment would be greater for the shock-delay groups.

Method

The apparatus has been described by Brown et al (1964). The rat is placed in the top half of a duplex start box. A warning buzzer sounds $7 \mathrm{sec}$ before the upper floor drops the animal onto the grid in the lower half of the start box. Leaving the start box the animal activates photoelectric relays on the $6-\mathrm{ft}$ path to the goal; 2-ft segmental running times in msec are printed out. Starting times are not recorded.

The Ss were 48 female hooded rats. Those in the first replication were 79-82 days old at the beginning of training; Ss in the second replication were 69-70 days old. Litter mates were distributed among conditions. One injured animal was replaced.

Animals were handled for three days prior to training. About one-third of them were permitted to explore the alley; however, exploratory behavior was quite variable and this procedure was dropped. On the fourth day the escape response was shaped by: (1) two trials with start box connected directly to the goal box; (2) three trials with a 2-ft alley between start and goal boxes; (3) three trials with a 4-ft alley; (4) two trials with the full alley. For the first five trials, the shock was $45 \mathrm{~V}$ ac (applied through a $10 \mathrm{~K}$ resistance); for the balance of the shaping trials it was $50 \mathrm{~V}$. On the fifth day, training with shock-onset delays of $0,1,2$, or 4 sec with $55-V$ shock began. Ten trials were given daily. The rats were run in squads and the intertrial interval was always at least $5 \mathrm{~min}$. Five days of training were given followed by four days of extinction-with-punishment testing in which a 55-V shock was present in the last $2 \mathrm{ft}$ of the alley adjacent to the goal box. Failure to enter the goal box within $60 \mathrm{sec}$ was the extinction criterion; Ss meeting this criterion were withdrawn from testing.

Results

Daily median running times were determined for individual $\mathrm{Ss}$, converted to speed scores, and averaged for groups. Acquisition data are shown in the left-hand panels of Figs. 1-3 for the three alley segments separately. Differences among groups emerged within the first day of training. The performance of the escape $(0-8 e c)$ group was relatively constant across days, although there was some tendency for speed in the third segment to fall off as training progressed. There was a clearly defined 1-2-4 order of speed for the shock-delay groups. Most of their nine acquisition curves rose gently.

Resistance to extinction is shown in Fig. 4. The overall variation of means was significant $(F=3.34$, df $=3 / 44, p<.05)$, and the escape-trained Ss showed less resistance to extinction than the shock-delay Ss $(\mathrm{F}=6.81, \mathrm{df}=1 / 44, \mathrm{p}<.05)$. The escape group differed reliably from both the 1 and $2 \mathrm{sec}$ delay groups at the .05 level; no other individual comparisons were significant. Extinction speed data are shown on the right in Figs. 1-3 for those Ss that continued to run. The acquisition ordering of delay groups was preserved for two days, although the differences in third segment speeds, where all Ss now received shock on 

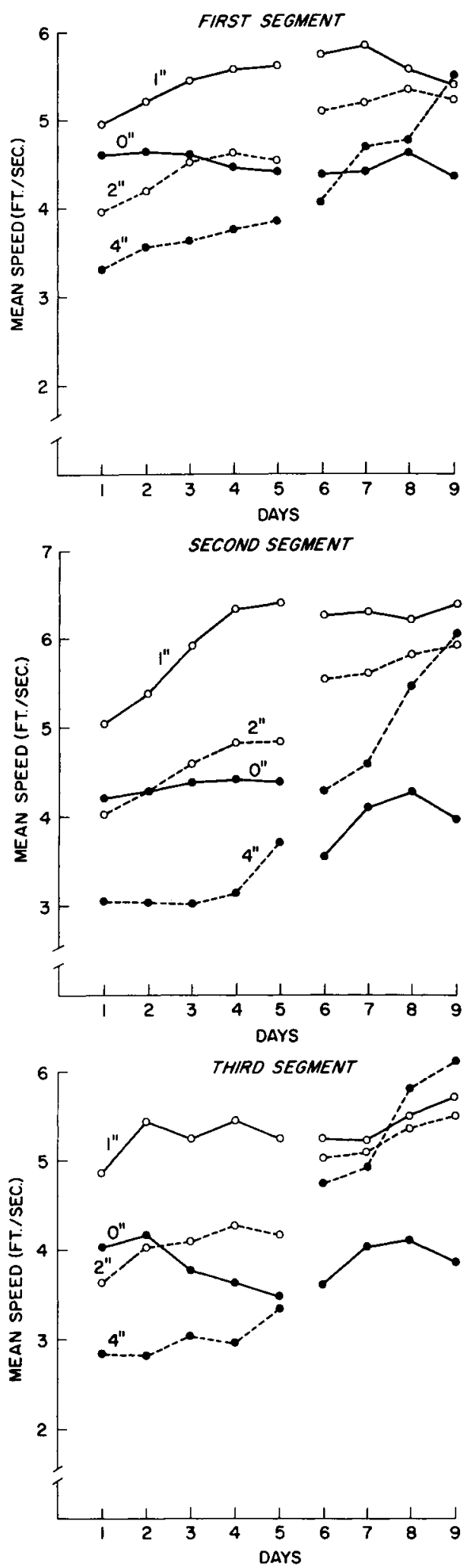

Figs. 1-3. Mean running speed in the first, second, and third segments of the alley during acquisition (left) and extinction (right). every trial, were attenuated. There was little change in speed of the 1-sec Ss during extinction. Both 2- and

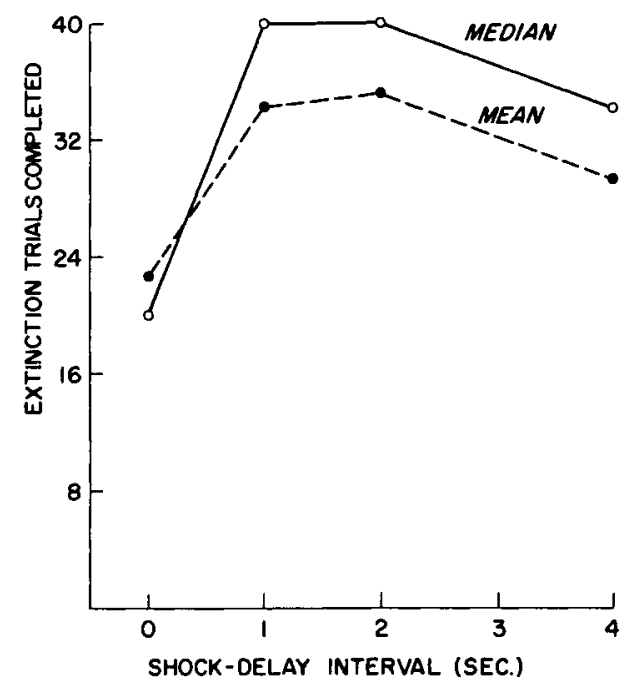

Fig. 4. Median and mean number of extinction trials completed by $S s$ in the several shock-delay groups.

4-sec groups increased speed, with the largest speed increments in the third alley segment where Ss were infrequently shocked in the later stage of acquisition. Discussion

The greater resistance to extinction for avoidancetrained Ss is consistent with previous studies in which extinction has been carried out without punishment (Sheffield \& Temmer, 1950; Jones, 1953; Santos, 1960). The maintenance of fast running or its development during extinction appears to be intimately related to persistence of running in both extinction cases. In our experiment, the avoidance-trained Ss either had learned to run faster during training, as in the $1-\mathrm{sec}$ and 2-sec conditions, or they learned to run faster during extinction, as in the case of the 4-sec Ss. During extinction, running faster reduces the punishment duration. This may be the reinforcement mechanism responsible for the learning of self-punitive behavior (cf., Beecroft \& Bouska, 1967).

\section{References}

Beecroft, R. S., \& Bouska, S. A. Learning self-punitive running. Psychon. Sci., 1967, 8, 107-108.

Brown, J. S., Martin, R. C., \& Morrow, M. W. Self-punitive behavior in the rat: Facilitative effects of punishment on resistance to extinction. J. comp. physiol. Psychol., 1964, 57, 127-133.

Brown, J. S., \& Van Bruggen, P. J. Avoidance-escape behavior as a function of delay of shock onset. Unpublished manuscript, 1967.

Jones, M. B. An experimental study of extinction. Psychol. Monogr., 1953,67 , No. 369 .

Santos, J. R. The influence of amount and kind of training on the acquisition and extinction of escape and avoidance responses. J. comp. physiol. Psychol., 1960, 53, 284-289.

Sheffield, F. D., \& Temmer, H. W. Relative resistance to extinction of escape training and avoidance training. J. exp. Psychol., $1950,40,287-298$.

\section{Note}

1. This research was supported by Grant $\mathrm{MH}$ 11734-02 from the National Institutes of Health to Judson S. Brown. We wish to thank Sally Bouska, Ann Stevens, Sharon Rolfson, and Warren Klare for their assistance. 